\title{
ACRL 13th National Conference Report
}

\author{
Jeanine M. Scaramozzino and Julia Gelfand
}

The city of Baltimore, Maryland, hosted the ACRL 13th National Conference, with the theme, Sailing Into the Future $\sim$ Charting Our Destiny, 29 March-1 April, 2007 at the Baltimore Convention Center. The record number of attendees included over 3,000 individuals representing 16 countries, with 318 new members and 1,008 firsttime attendees. This was one of the largest ACRL National Conferences and the range of programs and events reinforced this largesse, with a variety of programming options and ways to participate.

A number of innovative conference mechanisms were introduced at this conference including a first-time attendee orientation that involved meeting ACRL leaders, information on teaching and publishing, and discussions by various ACRL sections. The virtual conference components were enhanced and included live webcasts, blogs, polls, conference snapshots, and hot topic discussions. Cyber Zed Shed, a platform for demonstrating new technologies and their library applications, was an additional learning forum for conference attendees. The National Conference Wiki allowed participants to share Baltimore travel suggestions. Go to www.acrl.org/ ala/acrl/acrlevents/baltimore/baltimore. htm to link to the conference blog, conference wiki, watch video of conference highlights, purchase audio recordings of most conference programs, and download podcast interviews with Cyber Zed Shed presenters. Attendees of the physical and virtual conference can log in to ACRL's National Conference Online Community at http://home.learningtimes. net/acrlnational?invitation_key=2007acrl. This will allow you to access discussion boards, face-to-face ACRL National Conference and Virtual Conference presentation materials, presenter's images and biographies, and webcast session recordings.

Early arriving attendees were able to choose from six day-long preconferences. Activities included assessment effectiveness, outreach liaison strategies, digital copyright, and knowledge management. They also had the option of choosing one of three Baltimore exploration tours of famous landmarks and libraries.

The conference officially opened with remarks from Mary Reichel, the 13th National Conference Committee Chair and other ACRL leaders. Michael Eric Dyson, Avalon Foundation Professor in the Humanities, and University of Pennsylvania Professor of Religious Studies and Africana Studies, gave the opening keynote address. He spoke about the virtues and crises of hip hop culture, racial conflict and black identity and the role generational and racial differences have on the way students learn. He was incredibly passionate and presented much like a minister at a revival meeting. Reactions to Mr. Dyson's remarks varied greatly among conference attendees. A number of people left during his remarks while many were energized by his message. He has very strong opinions, and though I did not agree with all he said I found him entertaining and thought provoking.

The Opening Exhibits Reception that followed the keynote speaker featured more than 200 companies displaying and discussing state-of-the-art products and services for academic librarians and information professionals. Michael Eric Dyson was also available in the exhibit hall to sign his book, Pride: The Seven Deadly Sins.

The Friday luncheon opened with welcoming remarks from ACRL National Conference Chair Mary Reichel, ALA Executive Director Keith Michael Fiels, and ALA President
Leslie Burger. ACRL President-elect, Julie Todaro, presented Best Practices in Marketing Awards to Winston-Salem State University C.G. O'Kelly Library and Eastern Illinois University Booth Library. The featured keynote was given by John Waters, the Baltimore native, creator and director of a variety of films including A Dirty Shame, Desperate Living, Female Trouble, Pink Flamingos and Polyester and, most notably, the film Hairspray that was turned into a hit Broadway musical. A confessed bibliophile, he recounted some of his first experiences with books including illicit acquisitions. He made a number of unique suggestions for bringing people into the library and making books cool again including putting sticky notes in books to mark the dirty parts. He also made the statement, "It is impossible to commit a crime while reading a book". Later he was available for a book signing. Some attendees were horribly offended by his language and remarks, with some people exiting early. I found him terribly amusing and saw many of the conference, ACRL and ALA leaders laughing so hard I thought they would fall off their chairs onto the floor! He spoke to the fact that librarians need to participate in the reforming the images of books, libraries, and librarians.

The All-conference dessert reception was held at the National Aquarium in Baltimore, Saturday, March 31, 8:0010:00 p.m. and was a huge success and great fun. The aquarium's exhibits are designed to replicate natural environments from around the world and display more than 10,500 aquatic animals from mammals to invertebrates. It was a beautiful setting in which to celebrate. The place was packed and it was obvious from the general boisterousness that people were enjoying themselves. 
The closing keynote address featured Nina Totenberg, National Public Radio's (NPR) award-winning legal affairs correspondent. She explored the links between national public policy events and higher education. The limited effect of her speech and it its lack of focus was probably an artifact of her jetlag (she had just returned to DC from Asia) but the question and answer period was impressive. Her knowledge and experience reporting for NPR on the Supreme Court was evident in her responses to the audience's inquiries.

There were more than 250 programmes, including invited and contributed papers, poster sessions, workshops, panel and roundtable discussions, each discussing the issues presently affecting academic and research libraries. There were numerous topics discussed: using social networking sites to attract and inform patrons about campus libraries and services; innovative information literacy models, including online gaming; new assessment and collection resources; collection management strategies; and issues regarding open access and scholarly communication. Preregistration for the five workshops filled quickly, leaving many attendees to try and replace no-shows on the day of the workshop. Four poster sessions with over 150 presentations allowed students, new librarians and established career librarians to discuss their research and ideas. This was a very good way to encourage increased participation and for librarians to have a chance to share information widely, meet their counterparts and colleagues and get ideas to publish, promote, and advance their work.

There were four invited presentations during the conference.

Luz Mangurian, Professor Emerita, Towson University, presented "Learning, Emotion and their Application for Teaching", in which she discussed the neurophysiology of learning and the incorporation of that information into more efficient teaching paradigms. Standing up in front of a class and lecturing is not an effective model for student learning. Teaching styles and professors' attitudes must change to promote learning because discussion rather than lecturing promotes deeper retention and problem solving abilities. She discussed how students come to class with pre-conceptions about how things work and that the brain compares new information to previous information. Therefore, it is useful to ask students to compare similarities before asking them to contrast differences. "Ask students to consider an issue from different points of view to provide an opportunity for creating connections". Explanations of information might make sense to them, but their current misconceptions of information interfere with new knowledge. Thus it is important to utilize in-classroom activities in an effort to diagnose student's misconceptions and then work to overcome them. As a former scientist and someone currently involved in information literacy instruction it was great to see neurological evidence supporting what many educators already know, it is vital to involve students in the learning process.

David Silver's presentation, titled "Digital Media, Learning, and Libraries: Web 2.0, Learning 2.0, and Libraries 2.0", focused on this Assistant Professor of Media Studies at University of San Francisco's practical class assignments and class trips to the library which opened the eyes of students to the resources of the library. The presentation emphasized practical approaches to getting students into the library and using the resources. He discussed his philosophy of AEIOU, collective intelligence and Web 2.0, and the library strategies that use AEIOU. AEIOU stands for Already Existing Information Optimally Uploaded. One must "preserve memory in a culture of amnesia". One suggestion he made was to make information public by blogging. The internet already contains a collective intelligence and a great deal of hype surrounds Web 2.0. Web 2.0 already exists in numerous vehicles including Wikipedia, where users add and edit information, and people blog to learn information by "conversational" avenues instead of newspapers. Lastly, he discussed library strategies that he uses in his classes: requiring students to walk physically into the library and view exhibits, students must then "advertise" for the library as they blog about the experience and the exhibit. These conversations lead to suggestions of items that should be added to the collection. The collection is improved by students and students then feel that they are contributing and helping to construct the library, giving them a vested interest. Libraries need to understand that today's students like to talk about themselves. He has students find book reviews and then connect with the book by looking in the library catalog and finding the book on the shelf. This exercise helps draw kids from online into the offline world with an actual connection. He describes the library as the only truly interdisciplinary place on any campus through class exercises with his students. In addition, he teaches about blogging ethics and sharing information with privacy, selfrespect and asks students to determine whether something is potentially offensive without censoring themselves. He admitted that many of the students we are trying to reach are living in a culture of narcissism and technology. But, instead of passing judgment and sending students on a random fact finding assignment to learn what libraries resources are available, he outlined ways he teaches what libraries really have to offer by meeting students where they are, using technology, and involving them in the learning process so that they have a vested interest in what they are learning. He was one of the few presenters that did not philosophize about the way things should be in obtaining the goal of student information literacy, but look at things the way they are and found ways to circumvent problems and get to the goal.

Sanford Ungar, President, Goucher College (www.goucher.edu), "Education Without Boundaries: The Goucher Experiment" discussed the implementation of two important innovations at the college: a requirement that all undergraduates study abroad in order to graduate, and the construction of an Athenaeum at the center of campus that will include a state-of-the-art library. Globalization and its role in a liberal arts education was the focus of this presentation and service to students in preparation to going abroad as well as access to resources while abroad define the increasingly important role the library has in this new configuration of emphasizing curriculum, world history, current affairs, public policy, and information literacy.

Tracy Mitrano, Director of IT Policy and Computer Policy and Law 
Programs, Cornell University, presented "From Soup to Nuts: Copyright, Electronic Surveillance, and Social Networking Technologies". She clearly utilized her legal expertise (she has her JD) as she gave the audience a survey of the current digital copyright issues facing academic and research institutions, policy questions related to social networking technologies, and concerns with electronic surveillance. She ended with a salute to the profession, saying that libraries and librarians: have embraced new technologies and the opportunities they suggest for learning ... at the same time being mindful of the legal and political challenges that underpin these technologies given their particular tracking and surveillance capabilities; and lead the charge against the USAPatriot Act for its impact civil liberties by prompting debate, informing the media, and lobbying for reform. "You [librarians] are still charged with charting the direction for the constituents of colleges and universities to find meaningful access to information and, like Virgil guiding Dante, guiding us all through the pathways by which we continue to pursue our missions of teaching, learning and outreach". I hardily agree that there is a urgent need to integrate the "traditional values of libraries and the seminal role that they play in our democratic republican society with the age old missions of higher education in these interesting times that require us to balance law, technology, market forces and social norms in the name of an ethical ordered liberty".

The most substantive component of the conference was the interesting and numerous sessions, which often required attendees to choose between two concurrent sessions. Examples of the presentations include:

"Who do you trust?: Wikipedia and the authority of anonymous strangers", presented by Dan Ream, Head, Education and Outreach Services, Virgina Commonwealth University Libraries and Lucretia McCulley, Head of Outreach and Instruction Services, University of Richmond Library. The presenters had conducted an experiment that consisted of the videotaped interviews of students and professors about their use of Wikipedia. Analysis of clips showed Wikipedia is heavily used by both groups. Though how and why they use it varies. The majority of people used it as a starting point for research but not as a "cited source", though seven out of eight students did not realize that anyone can write and change Wikipedia entries. When informed of this fact, students feel empowered that they too could change or write an entry but a bit scared that "someone like them" was allowed. A major question in the digital age surrounds what will be an authoritative resource in the future.

"Adapting Best Practices to Global Perspectives: Developing and Assessing Information Literacy Learning in the Arab world" was a panel session presented by Daphne Selbert, Professor and Library Supervisor, Dubai Campus, Zayed University, UAE, Carol Hansen, Professor and Instruction Services Librarian, Weber State University, Ogden, UT (formerly with ZU), and Alison Armstrong, Information Literacy Department Head, American University in Cairo, Egypt. Their learning outcomes at the outset of these projects was the identification of information literacy assessment methods and resources that could be used in the Arab world and be flexible with specific regional issues. They discussed issues surrounding information literacy assessment and program development in the Middle East in order to engage authentically with colleagues in different regions and circumstances using ACRL best practices. They examined the award-winning online program used at Zayed University in a blended learning environment in order better to teach information literacy skills to second language learners. The information literacy program that Zayed University developed can be found at www.zu.ac.ae/infoasis/.

The intimate size of the audience allowed for an ongoing dialogue and questions during the entire presentation.

Another interesting program was delivered by three colleagues at the University of Southern California (www.usc.edu/libraries/). Robert Labaree, Sara Tompson, and Karen
Howell addressed "Effective practices for Technology-Enhanced Spatial Transformations", and promoted how reconfiguring space in a more technology-oriented environment effects collaboration, meeting pedagogical needs, and responded to users. Using information from the ARL LibQual Results and building on elements of the Strategic Plan, it was clear that new space needed to be shaped for added collections, a more digital presence and changing role of libraries on the campus. This presentation shared how three divisional libraries responded to different challenges posed by various physical configurations, new and emerging technologies, different student and learning agendas. The Leavey Undergraduate Library \& Information Commons, the newest library on campus at just over ten years old, installed a new podcasting studio to support students and faculty in the Schools of Architecture, Arts \& Sciences and Engineering and enhanced their Center for Scholarly Technology.

Powerpoint

presentations and handouts are available in the ACRL Virtual Conference Community at http://home.learningtimes.net/ acrlnational and session recordings of the Invited Paper Sessions, Panel Sessions, and many of the Contributed Paper Sessions can be purchased Conference Media at www.ConferenceMedia.net.

The 14th ACRL National Conference, "Pushing the Edge: Explore, Engage, Extend", will be held at the Washington State Trade Convention Center in Seattle, Washington, 12-15 March 2009.

Jeanine M. Scaramozzino (jscaramo @uci.edu) is a Reference Librarian at the University of California, Irvine Science Libraries and also at Saddleback Community College Library, South Orange County Community College District, Mission Viejo, CA, USA.

Julia Gelfand (jgelfand@uci.edu) is a co-editor, LHTN and a librarian at the University of California, Irvine. 